\title{
ANALYSIS OF THE NANOCRYSTALLINE PHASE FORMATION PROCESS IN AMORPHOUS $\mathrm{Fe}-\mathrm{X}-\mathrm{Si}-\mathrm{B}$ ALLOYS
}

\author{
Z. Stoklosa, P. KWapuliński, J. Rasek, J. Ilczuk aNd J. LelątKo \\ Institute of Physics and Chemistry of Metals, Silesian University \\ Bankowa 12, 40-007 Katowice, Poland
}

\begin{abstract}
The process of nanocrystalline phase formation, affecting magnetic properties, in amorphous $\mathrm{Fe}_{78} \mathrm{Si}_{8} \mathrm{~B}_{14}, \mathrm{Fe}_{76} \mathrm{Al}_{2} \mathrm{Si}_{8} \mathrm{~B}_{14}, \quad \mathrm{Fe}_{76} \mathrm{Cr}_{2} \mathrm{Si}_{8} \mathrm{~B}_{14}$ and $\mathrm{Fe}_{76} \mathrm{Mo}_{2} \mathrm{Si}_{8} \mathrm{~B}_{14}$ alloys has been studied in the paper. Investigations have been carried out using the electrical resistivity method, magnetic methods, transmission electron microscopy and X-ray diffraction. A nanocrystalline phase in the amorphous matrix has been obtained by isochronous or isothermal vacuum annealing. Phase composition of samples has been determined directly after manufacturing and after crystallization annealing on the basis of $\mathrm{X}$-ray diffraction and electron diffraction. Transmission electron microscopy was used to determine phase morphology, dimensions of formed nanocrystalline phase and transition phase. Alloying elements have been found to affect changes of magnetic properties in amorphous and nanocrystalline states. For $\mathrm{Fe}_{76} \mathrm{Mo}_{2} \mathrm{Si}_{8} \mathrm{~B}_{14}$ alloys a significant increase in crystallization temperature, making difficult nanocrystalline phase growth and increase in thermal stability of magnetic permeability have been observed.
\end{abstract}

PACS numbers: 75.50.-y, 72.15.-v

\section{Introduction}

During recent years materials of nanocrystalline structure have attracted considerable interest [1-3]. Advantageous magnetic and electric characteristics for these alloys may be obtained by choosing a suitable chemical composition. One of the nanocrystalline materials subgroups is the iron-based $\mathrm{Fe}-\mathrm{X}-\mathrm{Si}-\mathrm{B}$, where $\mathrm{X}$ signifies alloy addition atoms. A nanocrystalline state of the amorphous compound may be obtained by annealing at a temperature close to that of crystallization. It is important here to know the mechanism of formation of a crystalline compound on the amorphous base and to understand its influence on the physical properties of the alloys obtained. For an analysis of the formation of a nanocrystalline compound, transmission electron microscopy, X-ray structure analysis, Mössbauer effect, magnetic, electrical resistivity, internal friction, ultrasonic and calorimetric methods may be used [4-9]. 


\section{Materials and methods}

The alloys studied were obtained by rapid cooling from the liquid phase of the following chemical compounds: $\mathrm{Fe}_{78} \mathrm{Si}_{8} \mathrm{~B}_{14}, \mathrm{Fe}_{76} \mathrm{Al}_{2} \mathrm{Si}_{8} \mathrm{~B}_{14}, \mathrm{Fe}_{76} \mathrm{Cr}_{2} \mathrm{Si}_{8} \mathrm{~B}_{14}$, $\mathrm{Fe}_{76} \mathrm{Mo}_{2} \mathrm{Si}_{8} \mathrm{~B}_{14}$. Samples in the form of strips of width about $10 \mathrm{~mm}$ and thickness about $20 \mu \mathrm{m}$ were analysed using magnetic, electric, electron transmission microscopy and X-ray structure analysis methods.

Measurements of electrical resistance were performed in a circuit controlled by an IBM PC computer with automatic recording of results. Resistivity of the samples was studied by a static method using a four-point probe at room temperature or at temperature of liquid nitrogen, or in situ in a temperature range from 300 to $850 \mathrm{~K}$. A magnetic analysis was performed by a static method using an automatic maxwellmeter with digital recording and by a dynamic method in weak magnetic fields at a frequency of $1 \mathrm{kHz}$. The X-ray diffraction studies were performed by the Philips diffractometer with a diffracted-beam graphite monochromator using $\mathrm{Cu} K_{\alpha}$ radiation with a wavelength of $1.542 \AA$. A microscope analysis was performed using JEM-200B and JEM 3010 electron microscopes. Samples for microscope examination were polished using an ionic polishing machine of Gatan type. From the X-ray structure analysis and transmission electron microscopy it was ascertained that the samples in the as-quenched state had an amorphous structure. A crystalline phase on the amorphous base was obtained after isochronous or isothermal annealing in a vacuum.

\section{Results}

Magnetic and electric properties of the studied $\mathrm{Fe}-\mathrm{X}-\mathrm{Si}-\mathrm{B}$ alloys in the as-quenched state depend on the type of the alloy addition. To ascertain the structural changes taking place in these materials and to find a correlation between the results obtained in the various methods, magnetic, resistance, X-ray structure analysis and microscope methods were carried out at room temperature after isochronous annealing at temperatures from 300 to $850 \mathrm{~K}$. Figure 1 shows an example of normalized isochronous curves of magnetic permeability $\left(\mu_{n}\right)$ in the alloys studied. The results obtained show that the alloy additions influence both course and rate of structural relaxation and the course of the crystallization process. In Fig. 1 five zones $(I \div V)$ of changes in the magnetic permeability $\left(\mu_{n}\right)$ may be distinguished. The first zone features small changes related to the presence of structural relaxation, with their rate depending on the type of the $\mathrm{X}$ alloy addition. In the second zone an increase in magnetic permeability takes place, initially due to the disappearance of excess volume, then the formation of the nanocrystalline compound $\alpha-\mathrm{Fe}(\mathrm{Si})$. In the III zone there is a decrease in magnetic permeability resulting from the growth of the nanocrystalline compound $\alpha-\mathrm{Fe}(\mathrm{Si})$. In zones IV and $\mathrm{V}$ a decrease in magnetic permeability may be observed as the consequence of the formation of the crystalline compounds $\mathrm{Fe}_{3} \mathrm{~B}$ and $\mathrm{Fe}_{2} \mathrm{~B}$. From the results obtained it is clear that the alloy additions $\mathrm{X}$ influence the mechanisms of formation of the $\alpha-\mathrm{Fe}(\mathrm{Si}), \mathrm{Fe}_{3} \mathrm{~B}$ and $\mathrm{Fe}_{2} \mathrm{~B}$ compounds by affecting the diffusion processes in these materials. Aluminium atoms with their small atomic weight increase the activity of structural relaxation, while atoms of transient element $\mathrm{Cr}$ cause shifting the area of appearance of structural relaxation towards lower temperatures as 


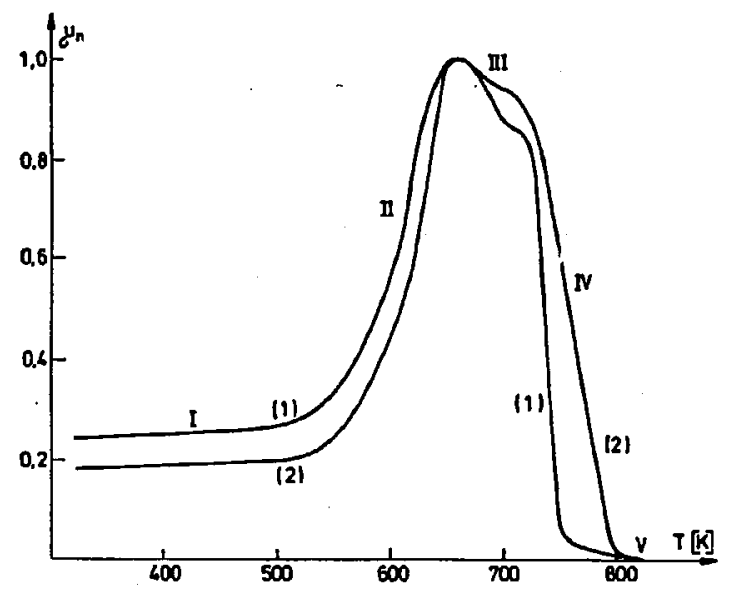

Fig. 1. Normalized isochronous curves of magnetic permeability for $\mathrm{Fe}_{78} \mathrm{Si}_{8} \mathrm{~B}_{14}$ (1) and $\mathrm{Fe}_{76} \mathrm{Mo}_{2} \mathrm{Si}_{8} \mathrm{~B}_{14}(2)$ alloys.

compared with $\mathrm{Fe}_{78} \mathrm{Si}_{8} \mathrm{~B}_{14}$ and Mo atoms, of relatively high atomic weight, reduce the rate of structural relaxation.

In the $\mathrm{Fe}_{76} \mathrm{X}_{2} \mathrm{Si}_{8} \mathrm{~B}_{14}$ alloys the values of resistivity $\rho$, a factor influencing the magnitude of eddy current losses are higher than for the $\mathrm{Fe}_{78} \mathrm{Si}_{8} \mathrm{~B}_{14}$ alloys. This is due to additional scattering of conduction electrons on the $\mathrm{X}$ atoms.

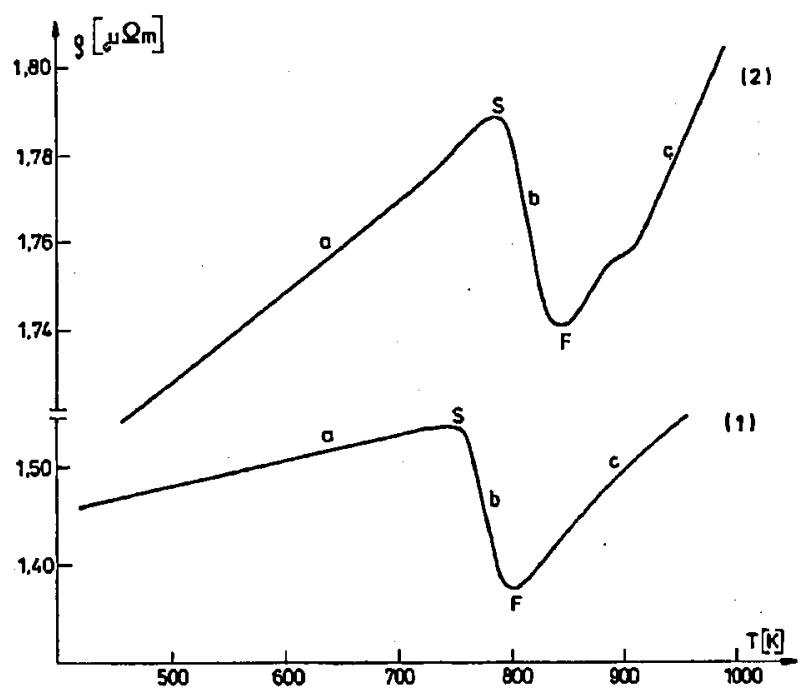

Fig. 2. Isochronous curves of electric resistivity in situ for $\mathrm{Fe}_{78} \mathrm{Si}_{8} \mathrm{~B}_{14}$ (1) and $\mathrm{Fe}_{76} \mathrm{Mo}_{2} \mathrm{Si}_{8} \mathrm{~B}_{14}(2)$ alloys. 
From measurements̀ of electric resistivity performed in situ with different rates of linear heating it was found that development of the crystalline compound is a thermally activated process. In Fig. 2 three zones of the change of electric resistivity $(\mathrm{a}-\mathrm{c})$ are discernible. The first zone (a) features an almost linear growth of $\rho$, associated with the scattering of conduction electron on the structure vibration. In the zone (b) a significant reduction of resistivity takes place, related to the formation of crystalline $\alpha-\mathrm{Fe}(\mathrm{Si}), \mathrm{Fe}_{3} \mathrm{~B}$ and $\mathrm{Fe}_{2} \mathrm{~B}$ compounds. The third zone (c) shows an increase in $\rho$ related to the scattering of conduction electrons on the vibration of the amorphous and crystalline structure, and the internal size effect $[5,10]$. A comparison of results of resistance measurements performed at room temperature with X-ray structure analysis shows that the crystalline compound $\alpha-\mathrm{Fe}(\mathrm{Si})$ appears at point $S$ (Fig. 2).

From the homologous point $F$ of the electrical resistivity curve, the average values of activation energy were obtained as follows: $E_{1}=(2.7 \pm 0.1) \mathrm{eV}$ for $\mathrm{Fe}_{78} \mathrm{Si}_{8} \mathrm{~B}_{14}$ alloy, $E_{2}=(2.9 \pm 0.1) \mathrm{eV}$ for $\mathrm{Fe}_{76} \mathrm{Mo}_{2} \mathrm{Si}_{8} \mathrm{~B}_{14}$ alloy.

\section{Discussion}

As mentioned earlier, improvement in magnetic properties of amorphous alloys may be obtained by the formation of a crystalline compound of a suitable size on the amorphous base. This phenomenon was observed for all the alloys studied here $\left(\mathrm{Fe}_{78} \mathrm{Si}_{8} \mathrm{~B}_{14}, \mathrm{Fe}_{76} \mathrm{Al}_{2} \mathrm{Si}_{8} \mathrm{~B}_{14}, \mathrm{Fe}_{76} \mathrm{Cr}_{2} \mathrm{Si}_{8} \mathrm{~B}_{14}, \mathrm{Fe}_{76} \mathrm{Mo}_{2} \mathrm{Si}_{8} \mathrm{~B}_{14}\right)$. However, the process of formation of the crystalline compound is very complicated and depends on the type of the alloy addition $\mathrm{X}$. The results of this study and data obtained from the literature indicated that the alloy addition influences the process of nucleation and growth of the crystalline compound, which is controlled by the phenomenon of diffusion (Fig. 1 and Fig. 2). The observed effect of an increase in magnetic permeability, is the result, among other things, of the influence of the crystalline compound on the effective anisotropy constant $K$ and the effective coefficient of magnetostriction. From the random anisotropy model the effective anisotropy constant may be written $[2,4]$ as

$$
\langle K\rangle=\frac{K_{1}}{\sqrt{N}}
$$

where $K_{1}$ is the local anisotropy constant of crystallites of dimension $D$, and $N$ is the number of crystallites in the volume $L_{\mathrm{ex}}^{3}$, where

$$
N=\left(\frac{L_{\mathrm{ex}}}{D}\right)^{3}
$$

The length of exchange interaction $L_{\mathrm{ex}}$ is

$$
L_{\text {ex }}=(A / K)^{1 / 2} \text {, }
$$

where $A$ is the exchange energy. If the dimensions of crystallites are smaller than the length of exchange interaction, the magnetic permeability has a value [1]

$$
\mu=p \frac{J_{\mathrm{s}}^{2} A^{3}}{\mu_{0} K_{1}^{4} D^{6}}
$$

where the coefficient $p$ is close to one, and $J_{\mathrm{s}}$ is the magnetization vector. In the case when $D>L_{\mathrm{ex}}$, then

$$
\mu=p \frac{J_{\mathrm{s}}^{2} D}{\mu_{0} \sqrt{A K_{1}}}
$$


From Eq. (4) it is clear that if the dimensions of the crystalline compound are small, the value of magnetic permeability obtained is large, while when crystallite dimensions increase, the magnetic permeability decreases. Thus, when the dimensions of the crystalline compound are smaller than the thickness of domains walls, a soft magnetic material is obtained. When the dimensions of crystal compound particles are comparable to those of the whole domains, the conditions for obtaining hard magnetic material are fulfilled.

The electron microscope examination confirmed this postulated rule of behaviour of magnetic permeability. As an example, the $\mathrm{Fe}_{78} \mathrm{Si}_{8} \mathrm{~B}_{14}$ alloy after annealing at $698 \mathrm{~K}$ features changes in its dark field in the amorphous state in the form of nanocrystallites (Fig. 3a). Under microscope examination visible changes were observed at $748 \mathrm{~K}$ (Fig. $3 \mathrm{~b}$ ). On the background of the amorphous base, crystallites of dendritic structure appear. A distinct process of crystallization may

(a)
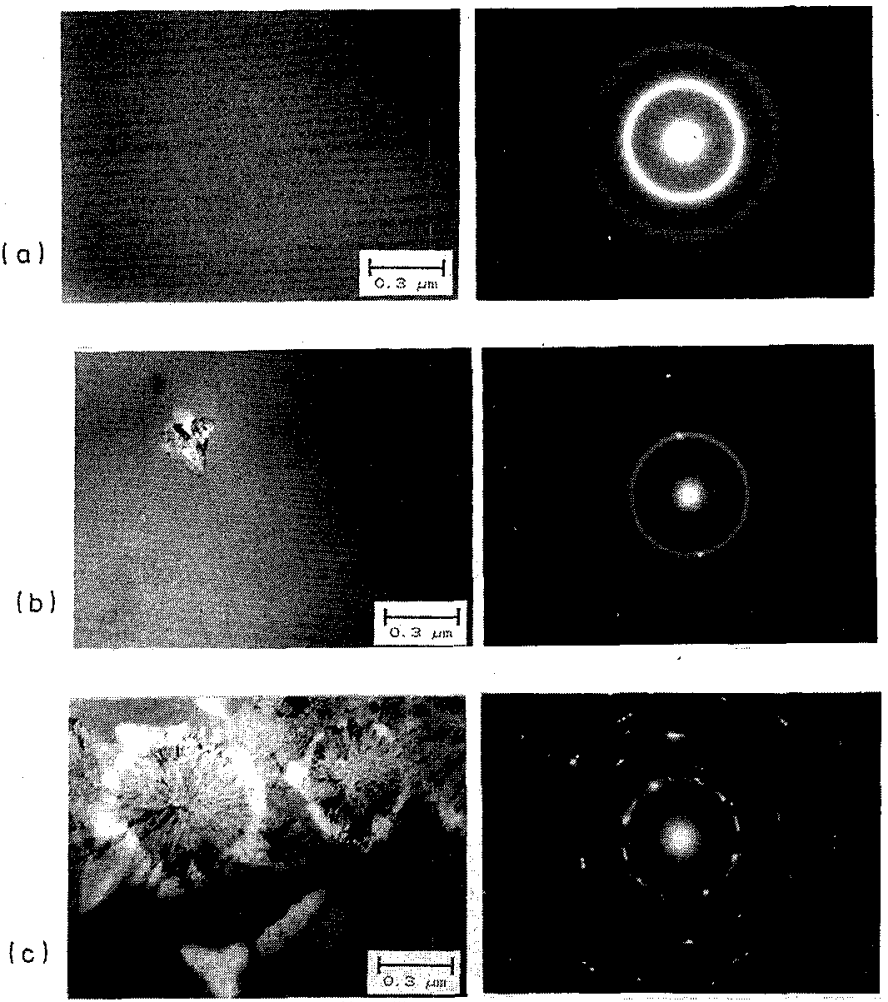

Fig. 3. Microphotograph on the dark field (left) and electron diffraction pattern (right) for $\mathrm{Fe}_{78} \mathrm{Si}_{8} \mathrm{~B}_{14}$ alloy after annealing: (a) at $698 \mathrm{~K}$, (b) at $748 \mathrm{~K}$, (c) at $773 \mathrm{~K}$. 
be observed at $773 \mathrm{~K}$ (Fig. 3c). As well as $\alpha$ - $\mathrm{Fe}$ (Si) dendrites also feathery forms of $\mathrm{Fe}_{2} \mathrm{~B}$ appear.

Apart from the phenomena mentioned above, changes in magnetic permeability depend on changes in the excess volume frozen out of the liquid phase during the rapid cooling. Magnetic after effects studies performed on these alloys have shown that the increase in magnetic permeability occurs in the temperature area, where the excess volume decreases.

\section{Conclusions}

1. Atoms of alloy addition $\mathrm{X}$ in amorphous alloys of $\mathrm{Fe}-\mathrm{Si}-\mathrm{B}$ type influence its magnetic permeability, electric resistivity and the phenomenon of structural relaxation, as well as the course of nucleation and growth of the crystalline compound.

2. Increased values of magnetic permeability during the isochronous and isothermal annealing of amorphous $\mathrm{Fe}_{76} \mathrm{X}_{2} \mathrm{Si}_{8} \mathrm{~B}_{14}$ and $\mathrm{Fe}_{78} \mathrm{Si}_{8} \mathrm{~B}_{14}$ alloys are associated with the disappearance of excess volume and formation of the nanocrystalline compound $\alpha-(\mathrm{Fe}(\mathrm{Si})$.

3. Atoms of molybdenum significantly inhibit the growth of the crystalline compound. The average activation energy of formation of the crystalline compound in the $\mathrm{Fe}_{78} \mathrm{Si}_{8} \mathrm{~B}_{14}$ alloy is $E_{1}=(2.7 \pm 0.1) \mathrm{eV}$, while for $\mathrm{Fe}_{76} \mathrm{Mo}_{2} \mathrm{Si}_{8} \mathrm{~B}_{14}$ it has the value $E_{2}=(2.9 \pm 0.1) \mathrm{eV}$.

\section{Acknowledgment}

This work was supported by the grant no. 7T08B04408 of the Committee for Scientific Research.

\section{References}

[1] R. Grössinger, Sato Turfeli, IEEE Transactions on Magnetics 30, 455 (1994).

[2] X.Q. Li, X.L. Yang, B.Y. Hu, Z. Wu, Y.Z. Zhang, H.J. Jin, G.Q. Xu, J. Magn. Magn. Mater. 145, 125 (1995).

[3] H. Kronmüller, J. Magn. Magn. Mater. 140-144, 25 (1995).

[4] B. Herzer, IEEE Transactions on Magnetics 25, 3327 (1989).

[5] K. Pękala, P. Jaśkiewicz, T. Kulik, Nanostructured Mater. 4, 707 (1994).

[6] K. Ishi, B. Cantor, in: Trends in Non Crystalline Solids, Eds. A. Conde, C.F. Conde, M. Milan, World Scientific, Singapore 1992, p. 161.

[7] Z. Kaczkowski, IEEE Transactions on Magn. 30, 103 (1994).

[8] M. Barandiaran, L.F. Barquin, J.C.G. Sal, P. Gorria, A. Hernando, Solid State Comm. 88, 75 (1993).

[9] G. Rionfino, G.W. Koebrugge, M. Baricco, J. Siestma, Phys. Status Solidi B 179, 315 (1993).

[10] P.L. Rossiter, The Electrical Resistivity of Metals and Alloys, Cambridge University Press, Cambridge 1987, p. 185. 